\title{
Las Defensas de la Costa Atlántica Andaluza
}

José Ramón Barros Caneda
uan Carlos Hernández Núñez

Historiadores del Arte

\section{Resumen}

A lo largo de estas páginas se hace un breve recorrido por las defensas que aún se conservan en la costa Atlántica de Andalucía, refiriéndonos a sus orígenes, sus características, su implantación en el territorio y su estado. El texto se ha articulado a través de diversas áreas definidas por aspectos funcionales y geográficos que les confieren unidad. Dichas áreas son la costa onubense; la barra del Guadalquivir; la bahía de Cádiz; las zonas de pesquerías y la bahía de Algeciras. En cada una se relacionan las principales construcciones existentes tratando de situarlas en su territorio y dotarlas de su sentido primitivo.

\section{Palabras clave}

Litoral de Andalucía Occidental / Costa atlántica / Arquitectura defensiva / Fortificaciones / Baluartes / Torres almenaras / Castillos / Dominio del territorio / Costa onubense / Barra del Guadalquivir / Bahía de Cádiz / Zonas de pesquerías / Bahía de Algeciras

Es un hecho constatado el gran valor estratégico de los territorios costeros. Sus ciudades, puertos al exterior y puertas del interior, han sido a lo largo de los siglos defendidas y conquistadas, destruidas y reedificadas en un continuo afán por incorporarlas a los dominios territoriales o bien por suprimirlas como espacios militares y comerciales.

Desde este punto de vista, la actual costa de Andalucía Occidental revestía y reviste un especial interés al ser el centro de conexión de lo mediterráneo, atlántico y africano. Ámbitos estos que, en determinadas etapas históricas y por unas razones u otras, alcanzaron diferentes grados de importancia. Su límite actual abarca desde la desembocadura del Guadiana, protegida por la ciudad de Ayamonte, hasta la bahía de Algeciras. En ese marco se sitúan distintas ciudades que de alguna manera poseen elementos de arquitectura militar en sus términos.

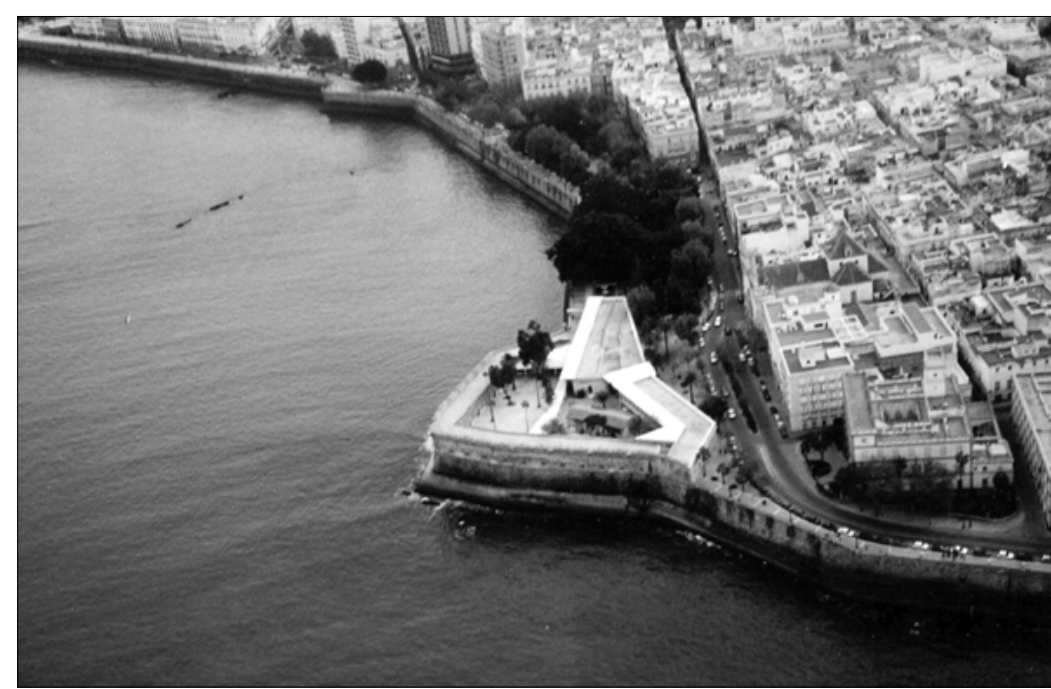

Esta arquitectura defensiva ha ido superponiéndose en capas históricas asentadas sobre el territorio en función de las necesidades defensivas o conflictos bélicos que se diesen en la zona. Por ello, en sus márgenes figurarán desde castillos, elementos generalmente individuales, propios de la sociedad feudal y vinculados con familias nobiliarias, hasta las fortificaciones generadas por un estado centralizado que dispone sobre su territorio un sistema defensivo complejo y conectado. En consecuencia serán variadas las tipologías arquitectónicas que se localizarán en este ámbito geográfico y cuyos orígenes estarán relacionados con ese aspecto de evolución histórica que hemos mencionado. Así nos encontraremos con castillos señoriales, fuertes, torres, murallas y baluartes. Unos y otros convertidos en importantes referentes de sus territorios a los cuales prestan identificación desde su presencia monumental y configuración tipológica.

Situados ya al margen de conflictos bélicos, han dejado de tener una misión defensiva y se han incorporado al paisaje a veces con nuevos usos y en la mayor parte de las ocasiones como señas de identidad históricas y culturales. Son arquitecturas descontextualizadas que han perdido su función de dominio sobre el territorio, quedando a veces absorbidas por las tramas urbanas, aunque nunca mudas por cuanto asumen esa función identificadora mencionada.

Por su parte los núcleos urbanos que las acogen, pese a su individualidad y singularidad, pueden agruparse en ámbitos territoriales más extensos, unidos, desde el punto de vista que tratamos, por relaciones funcionales y proximidades geográficas. De esta manera hablaremos de la costa onubense, desde Ayamonte a Almonte, zona tradicionalmente poco poblada y con munici-
I. Cádiz. Vista del Baluarte de Candelaria y de la zona oeste de la muralla.

Desde aquí queremos expresar nuestro agradecimiento a la Demarcación de Costas de Andalucía-Atlántico por la colaboración prestada al ceder y permitir la publicación de las fotografías aéreas que ilustran este texto. En concreto deseamos hacer extensiva nuestra gratitud a D. Santiago Montenegro Criado, Jefe de la Demarcación; a D. Francisco Hermoso Carazo, Dominio Público; a D. Juan Manuel Abarca Molina, Jefe de Sección del Servicio de Gestión del Dominio Público y a $D^{a}$. Soledad Bianchi Ardanaz, personal administrativo de la citada Demarcación, por el trabajo de localización y reproducción de las imágenes. Jefe de Servicio de Gestión del 

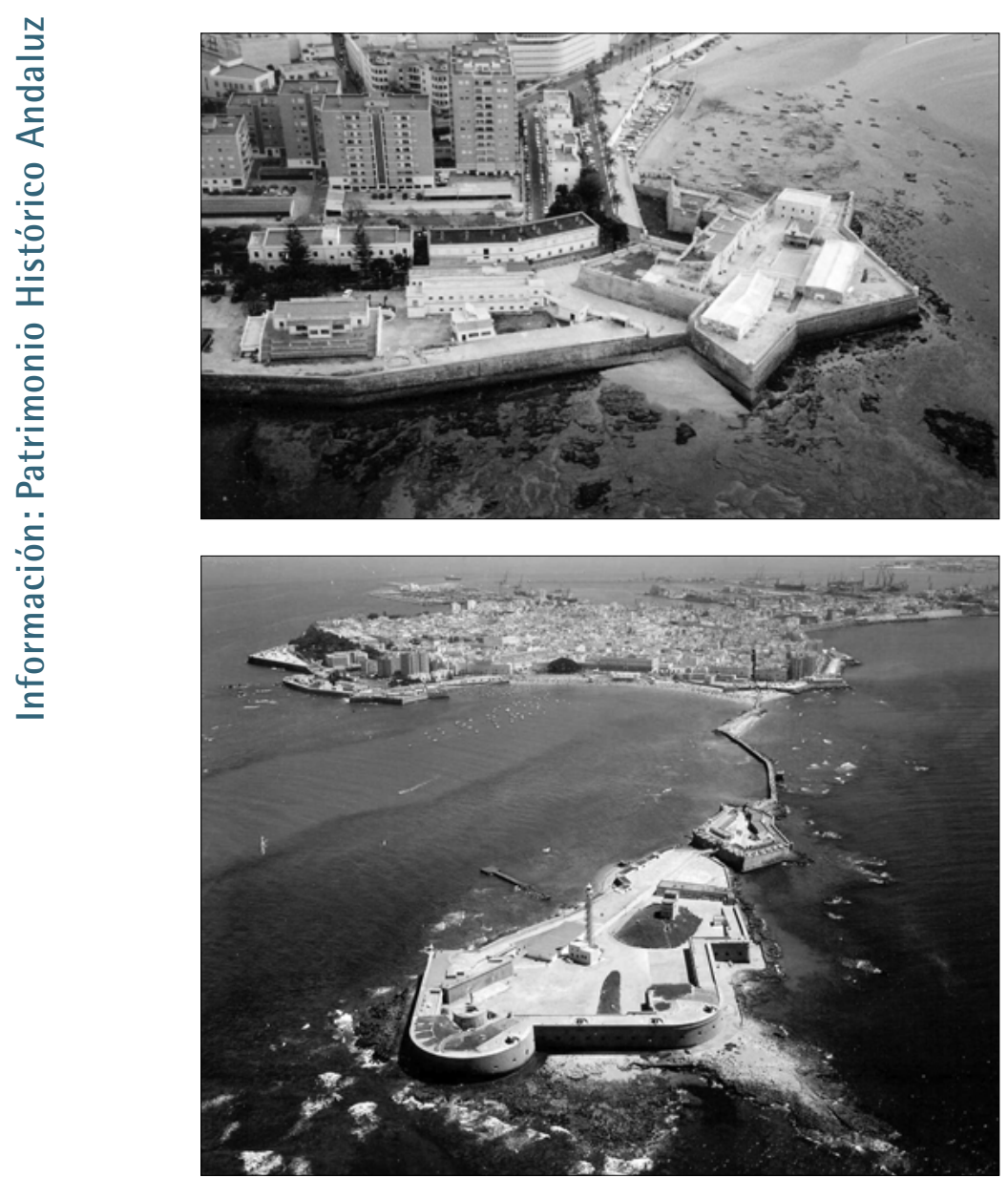

2. Cádiz. Vista del castillo de

Santa Catalina y parte de la playa de la Caleta.

3. Cádiz. Vista del castillo de San Sebastián y de la ciudad de Cádiz. pios dedicados a la pesca; la Barra del Guadalquivir, ámbito que abarcaría las poblaciones de Sanlúcar de Barrameda y Chipiona y que estaría relacionado con espacios pesqueros y esencialmente con la protección de la entrada al río. En tercer lugar diferenciaremos la Bahía de Cádiz como un núcleo territorial receptor de una intensa actividad comercial y, dentro de la reestructuración defensiva llevada a cabo por los Borbones, sede de instituciones militares que generaron la creación de numerosas arquitecturas y espacios de rango militar dentro de las poblaciones de Rota, Cádiz, San Fernando, El Puerto de Santa María y Puerto Real. Una cuarta zona caracterizada por la presencia de pesquerías y que quedaría constituida por las ciudades de Chiclana, Conil, Barbate, Vejer y Zahara de los Atunes. Y finalmente, la Bahía de Algeciras con las ciudades de Tarifa, Algeciras y la Línea, territorio fronterizo y puertas del Mediterráneo, intensamente vinculado a actividades comerciales y muy marcado por el conflicto bélico generado por el Peñón de Gibraltar.

\section{La costa onubense}

A pesar de su importancia estratégica por ser zona costera y frontera terrestre con el vecino reino de Portugal, sus defensas han sido bastante deficitarias a lo largo de la historia. Este amplio territorio costero que se extiende desde la desembocadura del río
Guadiana hasta la del Guadalquivir, estuvo prácticamente despoblado con extensas zonas deshabitadas durante toda la Edad Media y bien entrada la Moderna. Esta situación propició las continuas visitas, ataques y saqueos de los corsarios y piratas a los escasos y dispersos poblados existentes en la costa.

Las únicas edificaciones defensivas con las que contaba eran los castillos de origen medieval, si bien se encontraban alejados del litoral y protegiendo el ingreso de los principales ríos, verdaderas vías de penetración hacia las tierras del interior. En este sentido, pueden distinguirse tres núcleos fundamentales, el de Ayamonte, encargado de la protección del Guadiana, el de Lepe-Cartaya, a ambos lados del río Piedras, y el conjunto formado por Huelva, Moguer y Palos de la Frontera, que controlaban el acceso por los ríos Tinto y Odiel. Este precario sistema defensivo fue reforzado, a finales del siglo XVI y primer tercio del XVII, con la edificación de torres almenaras distribuidas a lo largo de la línea costera I. Su construcción se englobaba en un proyecto mucho más ambicioso, definido por la política defensiva de Felipe II, consistente en la creación de una línea de algo más de cuarenta torres que protegían el litoral desde Ayamonte hasta Gibraltar. Iniciado en 1576 no fue terminado hasta 1638, si bien algunas de las torres nunca llegaron a realizarse. En los siglos siguientes, se fueron acometiendo obras de menor envergadura, como adaptaciones y remodelaciones de algunas de las estructuras medievales a las nuevas artes de la guerra, permaneciendo éstas en vigor hasta, al menos, la Guerra de la Independencia.

Del conjunto defensivo de Ayamonte sólo se conserva la Torre Canela, en la isla de la que toma su nombre. El castillo, posiblemente levantado en el siglo $X I I I$ con diferentes modificaciones durante los siglos $\mathrm{XVI}$ al XVII y reconstruido tras el terremoto de 1755, fue completamente destruido en la segunda mitad del siglo $X X$ al construirse en su emplazamiento el actual Parador. De igual forma, tampoco se observan restos del conjunto de baterías, como la de las Angustias, a orillas del Guadiana, o las que se levantaron en las inmediaciones de su desembocadura. Por lo que respecta a la torre vigía presenta un único cuerpo troncocónico sobre un plinto circular, que interiormente se distribuye en un zaguán y dos cámaras superpuestas unidas por una escalera de caracol que termina en una garita sobre el terrado.

Siguiendo la costa, pero ya en el término municipal de Lepe, se encuentra la Torre del Catalán. Es de parecidas características a la anterior aunque algo más baja, al tener interiormente una sola cámara, y con una escalera que se desarrolla siguiendo la forma curva del muro. De los castillos medievales de Lepe y Cartaya, sobrevive el segundo que fue restaurado por la Consejería de Cultura a principios de los años 90. Es de planta rectangular con siete torres cuadradas, cuatro en las esquinas, dos al centro de los lados mayores y una al de los menores, protegiendo el acceso ${ }^{2}$. Su construcción hay que remontarla al siglo $\mathrm{XV}$, al crearse la población como plaza fuerte por Pedro de Estú- 
ñiga, conde de Plasencia. En los planos existentes desde mediados del siglo XVII, esta estructura estaba rodeada de otro recinto murario o falsabraga con baluartes triangulares, que en 1740 se encontraba "algo escarnada", al utilizarse de cantera para nuevas construcciones. Ese mismo año se le intenta devolver su utilidad militar al proyectarse en su interior la construcción de un cuartel de caballería, propuesta que no llegó a materializarse 3 . A las afueras de esta población, en la playa de El Rompido, se encontraba el castillo de San Miguel de Arca de Buey, del que sólo se sabe que fue destruido por los piratas holandeses en el siglo XVI y que sus restos fueron reaprovechados en I89| para construir el faro levantado en este lugar.

Al tercer núcleo defensivo, el del control del paso por el río Tinto-Odiel, pertenecen las torres de Punta Umbría y Arenillas, situadas respectivamente en los márgenes derecho e izquierdo. Al igual que las anteriores, presentan el cuerpo cónico cilíndrico, escalera de caracol y dos plantas con dos cámaras interiores la primera, y una, la segunda. Hay que señalar la inscripción, aunque muy borrosa, realizada en una placa de mármol, existente en la de Punta Umbría y que alude a su construcción en $16 \mid 4$, durante el reinado de Felipe III, ocupando el cargo de Juez de las Torres del Mar de Andalucía el licenciado Juan de la Fuente Hurtado.

De los tres castillos medievales, el de Moguer, datado a fines del siglo XIII o principios del XIV, se ha recuperado recientemente dedicándolo a actividades culturales. De proporciones pequeñas, tiene planta cuadrada con cuatro torres. Gracias a su utilización como bodega y a que en los muros perimetrales se apoyaron viviendas populares se ha conservado parte de éstos y tres de sus torres. Similares características y cronologías presentaban los desaparecidos castillos de Huelva y Palos de la Frontera, objetos de estudios arqueológicos en los últimos años ${ }^{4}$. De fechas más tardías, siglos XIV-XV, son los restos del castillo de San Fernando, observables sobre un cerro a la derecha de la carretera Palos-Moguer.

A lo largo de la amplia playa, conocida genéricamente como de Castilla, que se extiende desde la desembocadura del Tinto-Odiel hasta la del Guadalquivir, se encuentran las torres del Oro, Aspedillo, de la Higuera, Carbonera, de Zalabar y de San Jacinto. Por los cambios sufridos en el litoral con el paso del tiempo, permanecen casi intactas las de Carbonera, Zalabar y San Jacinto. Las tres presentan parecidas dimensiones, compuestas por una sola cámara y escalera de caracol de acceso al terrado. Por el contrario, de las del Oro, Aspedillo e Higuera sólo se conservan restos de las mismas, pues han sido "engullidas" por el mar. Los fragmentos de la segunda solo son visibles durante la marea baja. La del Oro presenta aún en pie parte del lienzo del cono, mientras que la de la Higuera, en la playa de Matalascañas, está volcada, en posición invertida, al menos desde 1756, ofreciendo a los visitantes la visión, poco común, de su cimentación y el arranque de su cuerpo troncocónico.

\section{La barra del Guadalquivir}

Este espacio de vital importancia comercial, estratégica y de comunicación se encuentra protegido por dos ciudades que dominan el acceso al río Guadalquivir. Nos referimos a Sanlúcar de Barrameda y Chipiona. En ambas se sitúan castillos vinculados a creaciones señoriales, destacando el de Santiago en Sanlúcar, que se localiza sobre una escarpa del Barrio Alto de la ciudad. Desde esa posición domina con su sólida presencia el Barrio Bajo de la ciudad y la desembocadura y acceso al río. Es una fortaleza de origen nobiliario, vinculada a la casa de Medina Sidonia, que fue construida en el siglo $\mathrm{XV}$, pasando a lo largo de los años por diversos propietarios y funciones. El castillo, de planta cuadrada, está articulado en torno a un patio central con torreones cuadrados y semicirculares en los muros y con una poderosa torre del homenaje que por su posición se convierte en una atalaya desde la que se domina la entrada al río.

Este entorno tan esencial, dado que protegía el acceso por el río hasta Sevilla, sede de la Casa de la Contratación hasta el siglo XVIII, contaba además a pie de costa con otros dos elementos que formaban parte de la infraestructura defensiva del río. Estamos hablando de

4. San Fernando. Vista del castillo de Sancti Petri.

5. Puerto Real. Vista de los restos del Fuerte de San Luis.
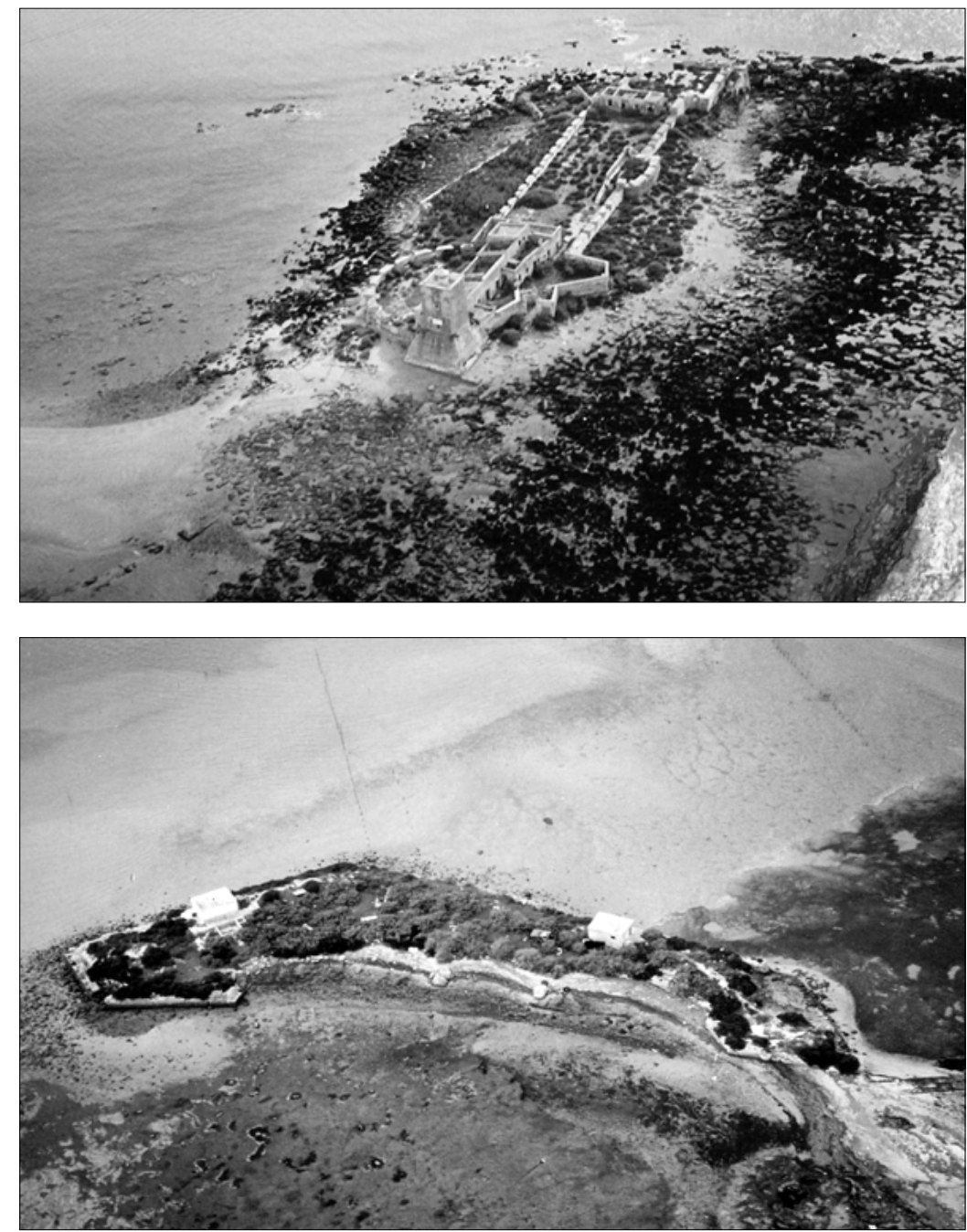

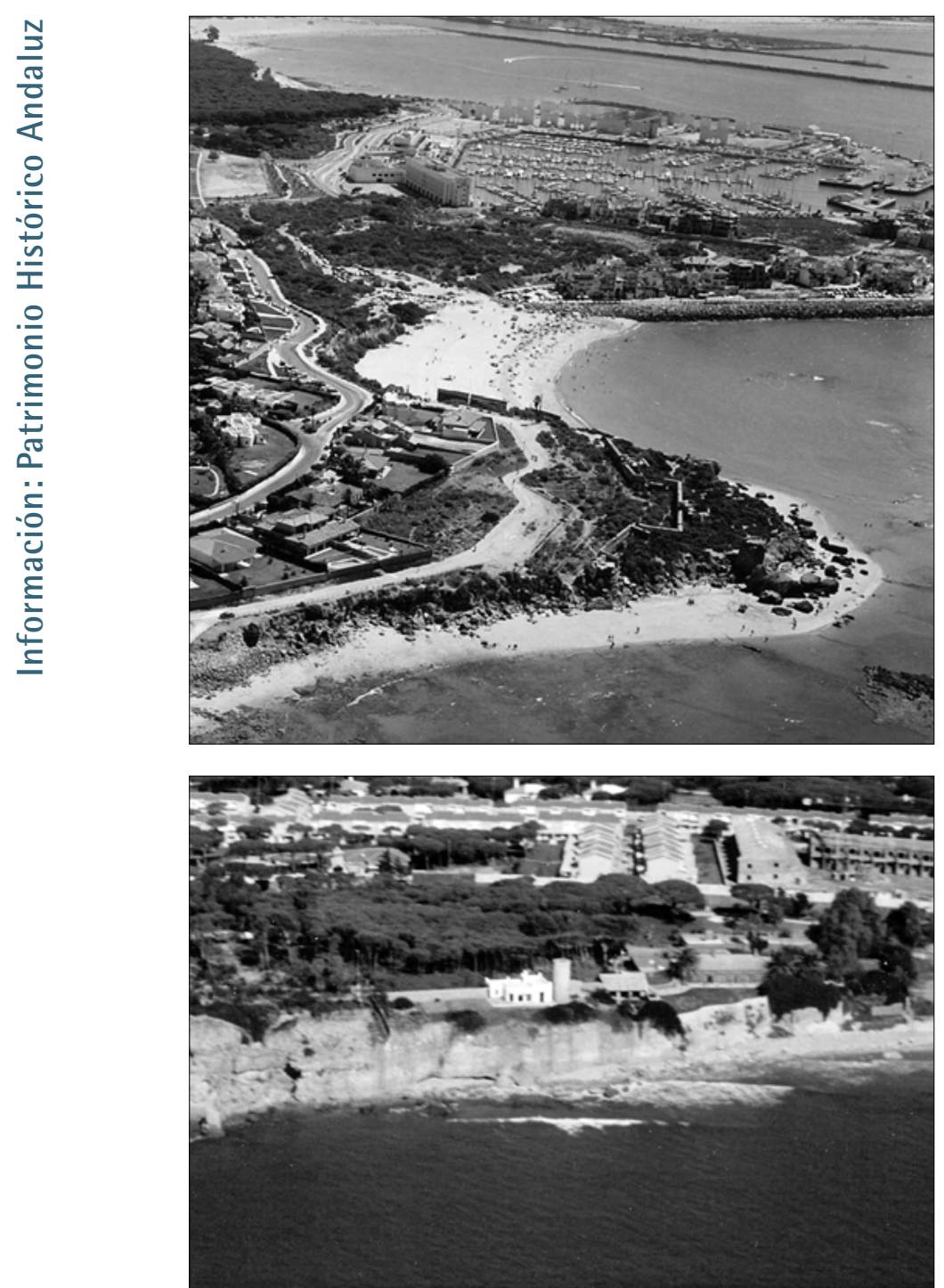

6. El Puerto de Santa María. Vista de los restos del castillo de Santa Catalina.

7. Chiclana. Torre Bermeja los fuertes de San Salvador situado en las proximidades del puerto de Bonanza, en el arranque del primer meandro del río, que presenta planta cuadrada con baluartes en los extremos, y cuyos muros, hoy arruinados, están en pie desde 1627 5, y el del Espíritu Santo ya desaparecido y que se encontraba ubicado en la desembocadura. Ambos se complementaban con torres situadas en la orilla opuesta del río.

Por su parte, Chipiona, desde su posición costera más que fluvial, dominaba la entrada marítima al río, destacando la presencia en el límite de la trama urbana y en conexión con el mar la figura de su castillo, también de origen nobiliario. Fue edificado en el siglo XIII protegiendo con su presencia los corrales de pesca que se situaban en la línea de costa, así como el frente costero. El castillo dominaba desde la línea de costa el espacio marítimo que antecedía a la entrada al río, la cual estaba conformada por una barrera natural de arenales que hacían compleja la navegación, lo cual suponía ya una buena defensa. Por ello, durante el siglo XVIII se quiso construir un faro artillado para facilitar la navegación, aunque no fue hasta el siglo siguiente que se erigió el actual Faro de Chipiona.

\section{La bahía de Cádiz}

Este núcleo territorial marcado por un contorno geográfico muy preciso resultó de gran interés para la construcción de una política defensiva y militar no sólo de esta área, sino del conjunto del estado. La ciudad de Cádiz, como aglutinador, ha tenido desde siempre una excepcional importancia comercial y defensiva en el contexto de una amplia bahía surcada de ciudades entre las cuales surgieron intensas relaciones, de las que las defensivo-militares han dejado una impronta que se extiende hasta nuestros días. De hecho, algunas de las arquitecturas, surgidas al hilo de esta cuestión, aún forman parte y se siguen usando en el marco de la política de defensa del país.

Haremos primero mención de Rota. Una ciudad situada en la costa y que abría la entrada a la bahía. Su castillo, llamado de Luna, asentado en las proximidades del mar fue fundado sobre un ribat musulmán durante los siglos XIII al XVI bajo los auspicios de Guzmán El Bueno, como parte de la cerca o muralla que envolvía la primitiva urbe. Es de planta rectangular con cinco torreones y su interior se articula en torno a un patio central.

Por su parte, Cádiz fue tradicionalmente una ciudad asediada y combatida. Ante sus murallas se situaron ingleses, holandeses y franceses, de ahí la imperiosa necesidad desde fecha muy temprana de fortificarla, creándose, por ello, una secuencia de amurallamientos que dieron a la ciudad una imagen muy característica. El primitivo núcleo poblacional -actual barrio del Pópulo- aún conserva las tres puertas de acceso de sus murallas, los llamados Arcos del Pópulo, de la Rosa y de los Blancos. La trama urbana ha respetado, en buena medida, el trazado de la antigua muralla de tal manera que, en la actualidad, el Pópulo se conforma como un espacio urbano con rasgos propios y protegido por el propio sentido de cerramiento de la muralla.

Tal vez sea la sólida presencia arquitectónica de las murallas una de las constantes que han marcado a Cádiz. El permanente cinturón de murallas, pese a las progresivas expansiones urbanas, siempre aparece como límite y barrera de la misma. Tal y como el citado barrio del Pópulo tuvo su muralla, la ciudad de los siglos XVI, XVII y XVIII también quedó paulatinamente cercada por un potente muro defensivo perimetral que remarcaba aún más el sentido de isla. Pero todavía en el siglo XIX y debido a la invasión francesa se hizo necesario extender más el perímetro amurado llevándolo a la zona de Cortadura, murallas que aún existen y que cierran el acceso de la ciudad contemporánea.

Desde este punto de vista ese límite arquitectónico y visual que suponían las murallas se ha convertido en una constante psicológica que en épocas pasadas se vio contrarrestada por el flujo y el trasiego portuario que generó comunicación de ideas, formas, estilos. En cualquier caso, las murallas se han convertido en un referente visual y arquitectónico que forma parte de las señas de identidad de la ciudad. 
En ese sentido, la ciudad histórica queda escindida del resto por el Frente de Tierra, comúnmente llamado "Puertatierra". Esta parte de las murallas fue la que mayor número de intervenciones y reformas tuvo, quedando su configuración fijada a mediados del siglo XVIII con dos baluartes, llamados de San Roque y Santa Elena, unidos por un lienzo de muralla con la puerta de la ciudad y un pesado torreón defensivo sobre ella ${ }^{6}$. El Frente de Tierra permaneció intacto hasta que en la década de los cuarenta del siglo pasado fue horadado por dos amplios arcos que permitían la comunicación viaria con la tercera zona de expansión de la ciudad. Con el mismo sentido se derribó parte del baluarte de San Roque.

Desde este punto la muralla se extendía envolviendo toda la isla gaditana. En la actualidad sobrevive buena parte de ella, tan sólo ha desaparecido el frente portuario del que se mantiene el baluarte de San Carlos -las murallitas de San Carlos- que fue realizado en 1784 incluyéndose en su interior cinco manzanas de viviendas particulares ${ }^{7}$, y cuya muralla fue también perforada por sendos arcos que facilitan el tránsito viario. Desde este baluarte arrancaba toda la zona oeste del cinturón amurado, es decir, el frente marítimo que protegía la entrada al puerto y que estaba constituido por diversos tramos dominados por baluartes de entre los que destaca el $\mathrm{Ba}$ luarte de Candelaria que ha sido recuperado para la ciudad como espacio cultural. Originalmente se levantó en 1672 a iniciativa del gobernador de Cádiz, Diego Caballero de Illescas, con la intención de proteger la entrada natural al puerto de Cádiz. Dada su posición, sufrió los continuos embates del mar, siendo ingenieros militares de la talla de Ignacio Sala, Juan Zapatero y Antonio Hurtado los que ejecutaron las reparaciones.

El baluarte se presenta como un saliente de la muralla que aprovecha la disposición geográfica del terreno. Es de planta irregular y adopta forma apuntada para afrontar la fuerza del mar. Su muralla forma talud y en la parte inferior muestra una plataforma a modo de rompiente del oleaje. Sobre la muralla se eleva una crujía con cañoneras en cuya parte superior se sitúa el camino de ronda. El conjunto queda cerrado, en la parte que mira a la ciudad, por diversas dependencias como el cuerpo de guardia, la casa de bombas, etc

El siguiente punto importante de esta zona era la Caleta, un ámbito, en la actualidad de especial relevancia para la ciudad, que se encuentra flanqueado por el castillo de San Catalina, obra del ingeniero Cristóbal de Rojas y cuya planta estrellada recoge la más pura tradición de los sistemas de defensa renacentistas. Se terminó de edificar en 1598 con la intención, dentro del plan de fortificación de la ciudad, de proteger la entrada por la zona de La Caleta. En 1693 se construyó la capilla y algunos alojamientos y hoy día esta siendo rehabilitado por una Escuela Taller.

Frente a él y dominando el otro flanco de la Caleta se sitúa el castillo de San Sebastián. Un espacio de continuos asentamientos desde la antigüedad. Sede del templo de Kronos, de una torre-atalaya musulmana y ya en el siglo XV lugar de una ermita advocada a San Sebastián. En 1613 se construye un faro, en 1706 se inician las obras del actual castillo y durante el siglo XIX se realizó el camino que lo une a la puerta de La Caleta. Consta de dos espacios abaluartados asentados en cada una de las isletas. El primero, el verdadero castillo, es de planta irregular, abaluartado con garitas, con portada de acceso y con dependencias en torno a un espacio central también de carácter irregular. Unida a ella, se encuentra la segunda isla, igualmente amurada, y donde se yergue el actual faro, construido en 1908.
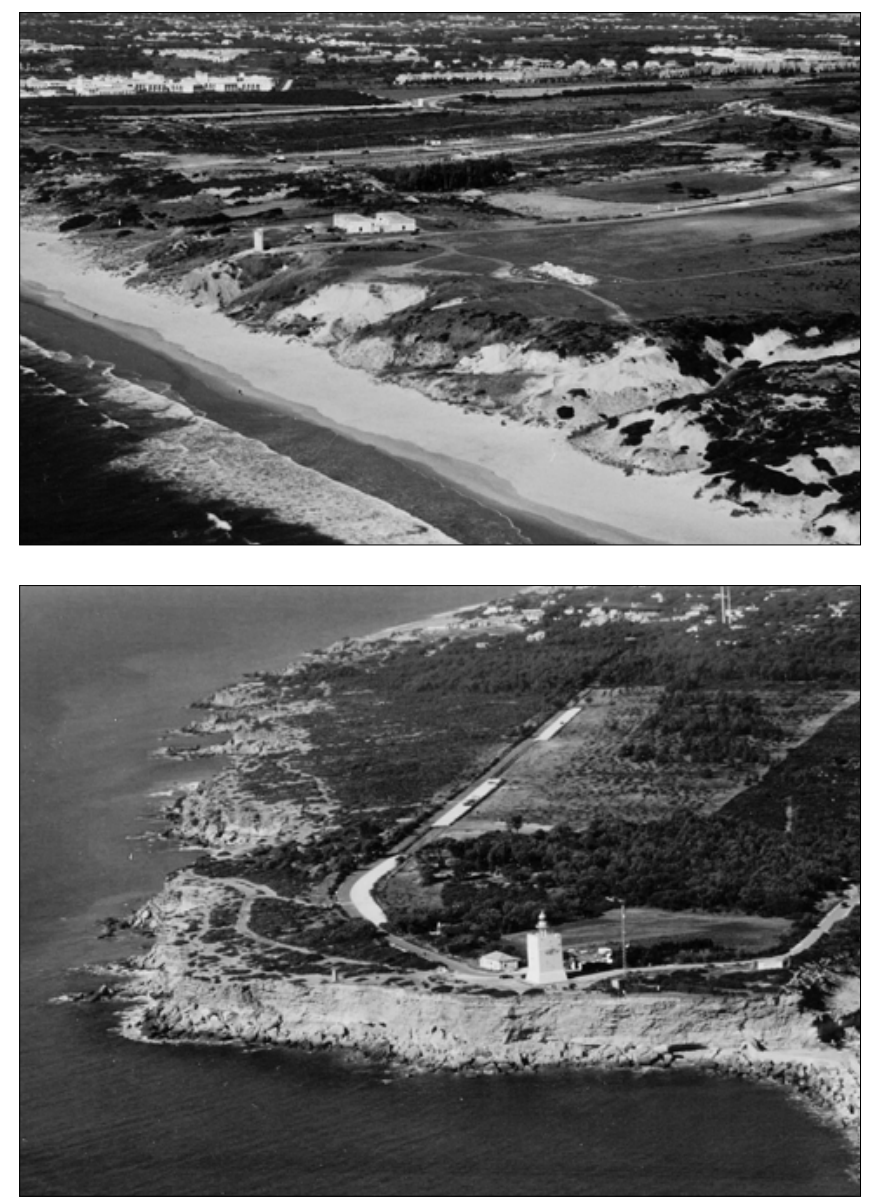

El último tramo de la muralla es el correspondiente 8. Chiclana. Vista de la Torre del Puerco. a la parte sur y que recibe el nombre de "Murallas de Vendabal" o Campo del Sur. Si la presencia del mar siempre suponía un reto para las obras, esta zona es la que mayores problemas generó. Tras numerosos derrumbes, su amurallamiento había quedado paralizado a finales del siglo XVII. En 1719 se realizan nuevos intentos que quedan paralizados en 1723, intentándose en 1747 nuevas reparaciones. Pero el gran interés por cerrar esta parte de la isla llegó a raíz del temporal acaecido en 1765. Como consecuencia del mismo se suceden intervenciones de los ingenieros militares Juan Caballero, Silvestre Abarca, Luis Huet, Juan Martín Cermeño. Pero fue Tomás Muñoz el encargado en 1788 de llevar a cabo el proyecto de reconstrucción que se extendió 

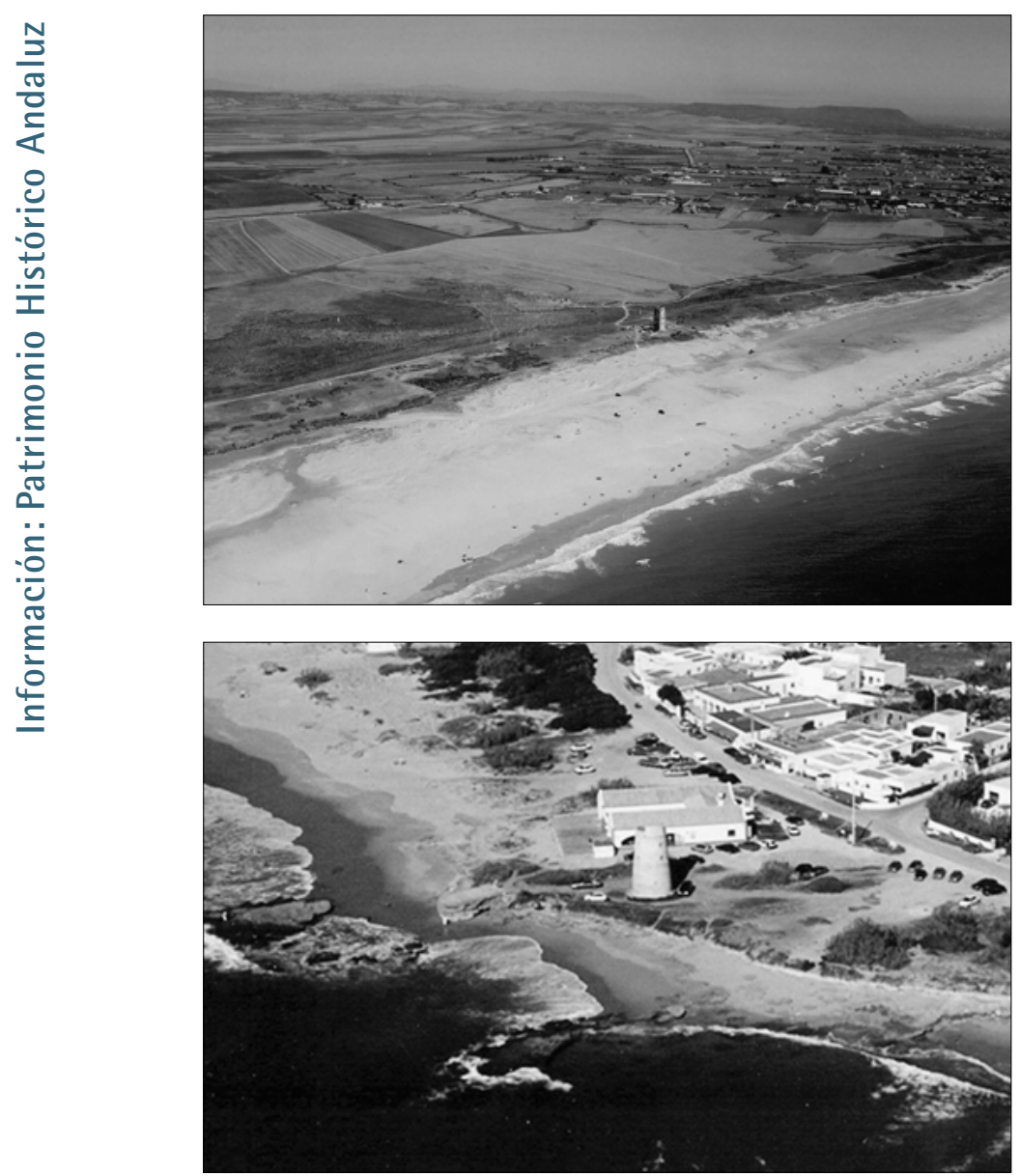

10. Conil. Vista de la Torre de Castilnovo.

II. Vejer. Torre Nueva. hasta |79|, abarcando la zona comprendida entre el flanco del Matadero y el flanco de Capuchinos. Su idea era crear una playa artificial tras la cual un batidero daría paso a la muralla. Tomás Muñoz consiguió cerrarla, pero en 1792 ocurrieron nuevos derrumbamientos por la fuerza de la mar. Durante el siglo XIX las fracturas continuaron, casi siempre en la misma zona, pero el trazado ya estaba realizado definitivamente. Este comprendía los baluartes de los Mártires y Capuchinos y los flancos de Capuchinos, San Rafael, San Nicolás y del Matadero.

Desde este punto enlaza la muralla con el Frente de Tierra dándose por cerrado el cinturón amurado de Cádiz. Sin embargo, como dijimos anteriormente, no concluyeron aquí las tareas defensivas. Durante el siglo XIX fue necesario ampliar el cerco de murallas hasta la entrada del camino que conducía a la vecina ciudad de San Fernando. La conocida como Muralla de Cortadura fue un proyecto diseñado en I 801 por el ingeniero militar Antonio Hurtado. Hasta 1808 no se iniciaron las obras de construcción bajo la luz de un proyecto que planteaba una fortificación con dos baluartes que hacían frente a la entrada de San Fernando y otros dos que se expandían a los lados. De esta manera se protegía el único acceso terrestre y sus flancos de la playa y la bahía. Las obras no estuvieron concluidas hasta $|8| \mid$ faltando el baluarte que protegía el lado de la bahía y que se proyectó de nuevo con vistas al asedio fran- cés de la ciudad. En la actualidad marca el límite urbano de la ciudad conservándose los baluartes, aunque su interior está ocupado por instalaciones sociales del Ministerio de Defensa.

Finalmente es interesante mencionar la existencia de fuertes que dominaron el acceso a la bahía. De todos ellos aun pervive el Castillo de San Lorenzo de Puntales, más conocido como el Castillo de Puntales. Este enclave defensivo se remonta al siglo XVI. En 1587 consistía en un torreón artillado con cinco cañones que fue casi destruido en el ataque de I596. Fue reconstruido en 1598 por el ingeniero Cristóbal de Rojas y terminado en 1613 . Sucesivos ataques durante los siglos siguientes condujeron a una nueva reconstrucción en 1863 que le dio su configuración actual. Hoy día, aún en uso como dependencia del Ministerio de Defensa, presenta planta ovalada precedida por dos baluartes entre los que se encuadra la puerta de acceso. Situado en una punta de tierra que estrecha el acceso al interior de la bahía, sus funciones defensivas se complementaban con los fuertes de San Luis, cuyos restos aún pueden contemplarse, Matagorda y las defensas de la isla del Trocadero ubicados todos en el lado opuesto de la bahía. Todos ellos formaron en conjunto un sistema de defensa de la entrada a la bahía gaditana, en la que con el tiempo se desarrolló una importante industria naval que se concretó en la construcción del primitivo Carenero del Puente Suazo, posteriormente, durante el siglo XVIII, el Arsenal de la Carraca y ya más recientemente los Astilleros de Cádiz y Puerto Real.

Antes de continuar con los elementos defensivos que componen el litoral hay que mencionar la presencia de tres núcleos de población muy importantes que forman parte del conjunto de la bahía y que de una forma u otra se integraron en su proceso defensivo. La bahía es un espacio geográfico circular que ha generado en su perímetro diversas poblaciones volcadas, de una manera u otra, hacia ella. Nos referimos a San Fernando -antigua Isla de León-, Puerto Real y El Puerto de Santa María. Cada una con elementos defensivos de interés.

San Fernando, además de la mención que hemos hecho a la construcción naval, contiene varias claves para el sistema defensivo de la zona. Rodeada por la bahía y por el río Sancti Petri, adquiere una configuración de isla y se convierte en paso obligado hacia Cádiz por cuanto es su única vía de acceso terrestre. Este sentido de tránsito vivido como "entrada o salida hacia", remarcado por la disposición longitudinal de su territorio configuró un urbanismo asentado sobre el camino a Cádiz, adoptando la disposición de ciudad-calle, siendo esto una marca caracterizadora de la ciudad. De este modo se convertía en el cuarto nivel defensivo de Cádiz, nivel que comenzaba en el Puente Suazo. Este, que sortea el río Sancti Petri, situado a su entrada quedó defendido desde épocas medievales por el castillo de San Romualdo vinculado a los Ponce de León y hoy en proceso de recuperación, añadiéndose durante los siglos siguientes ba- 
terías que protegían la cabecera del puente. Tal es el caso de las llamadas de San Pedro y San Pablo cuyos restos aún perviven asentados en las marismas que dominan la entrada al puente, pero con una posición hoy desvirtuada por los nuevos trazados viarios que se han ejecutado.

Por su parte, el río Sancti Petri, que comunica el mar con la bahía flanquea toda la zona este de San Fernando, mostrando en su conexión con el mar dos arquitecturas que vigilan ese importante espacio de penetración fluvial. Hablamos de la batería de Urrutia arquitectura abandonada y envuelta en la maleza, pero que conserva su estructura formada por un potente lienzo de muralla que adopta forma curva y un amplio patio de armas cercado ${ }^{8}$, así como del castillo de Sancti Petri ubicado en un islote a la desembocadura del río. Arquitectura mítica -se habla del Templo de Hércules- fue modificada durante los siglos XVIII y XIX para adaptarlo a las necesidades de defensa de su posición marítima, destacando por su privilegiada posición geográfica y por una sólida torre de paramentos lisos que establece conexión con la línea de torres costeras. Su arquitectura adopta la disposición del islote en que se sitúa, adquiriendo así una planta longitudinal con sendos baluartes en los extremos, destacando uno semicircular que defendía el acceso desde tierra y junto al que se elevaba la torre. En la actualidad mantiene la planta que adquirió en los años finales del siglo XVIII, si bien su estado de conservación es bastante deficiente.

La posición geográfica de Puerto Real, situado su término municipal frente a Cádiz, le convertía en el complemento idóneo para defender la entrada de la bahía. Así surgieron a lo largo de los siglos diversos fuertes que junto con el ya citado de Puntales defendían la puerta de la bahía. Estos fuertes fueron los de San Luis y Matagorda, a los que hay que añadir los diversos intentos de fortificación de la isla del Trocadero. Del primero aún puede contemplarse los restos de su estructrura formada por una planta poligonal con un patio interior de semejante disposición formado por soportales sobre los que corría el paseo de armas.

El Puerto de Santa María, la tercera urbe conectada con la bahía, estaba especialmente vinculada con el río Guadalete en cuya ribera se fundó, tomando al castillo de San Marcos como hito de referencia. Es éste un inmueble de origen medieval construido sobre una primitiva mezquita, con dominio sobre el río y la propia ciudad, y que se convirtió con el tiempo en referente icónico de El Puerto de Santa María. Sin embargo, la clave en la defensa de la bahía y el acceso al río lo formaba un grupo de baterías que surcaban la costa desde Rota hasta El Puerto: la Gallina, la Puntilla, el Palmar, la Bermeja, la Ciudad y la Arenilla, todos pequeños recintos artillados que dirigían su línea de fuego hacia la bahía 9. y cuyo sistema de protección culminaba en el castillo de Santa Catalina. Este se encontraba situado en una punta del litoral y sus ruinas, que se conservan aunque casi absorbidas por el empuje urbano, muestran los restos del frente abaluartado de tierra y de la muralla del frente de mar. En su interior se disponían las dependencias entre las que se encontraba una iglesia y una torre de planta circular, cuya base desmochada aún existe 10

\section{Áreas de pesquería}

Dejando a un lado la bahía y su complejo sistema defensivo, hacia el sur se sitúan diversas ciudades vinculadas a actividades pesqueras y almadrabas. Nos referimos a Chiclana, Conil, Barbate, Vejer y Zahara de los Atunes. En este tramo los sistemas defensivos van ser de menor entidad que los vistos hasta ahora, pero en conjunto representan un interesante sistema de pequeñas torres individuales de observación situadas en puntos estratégicos de la costa y que entrelazaban su dominio visual y comunicativo, extendiéndose por todo el frente atlántico y el mediterráneo. Dichas atalayas o torres almenaras " -así llamados por las hogueras que se encendían como sistema de comunicación visual- marcan una línea defensiva continua, cuyo valor residía, como decimos, más en el dominio visual del territorio que en el militar, aunque en ocasiones se mezclaran

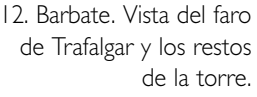

13. Barbate. Torre del Tajo.
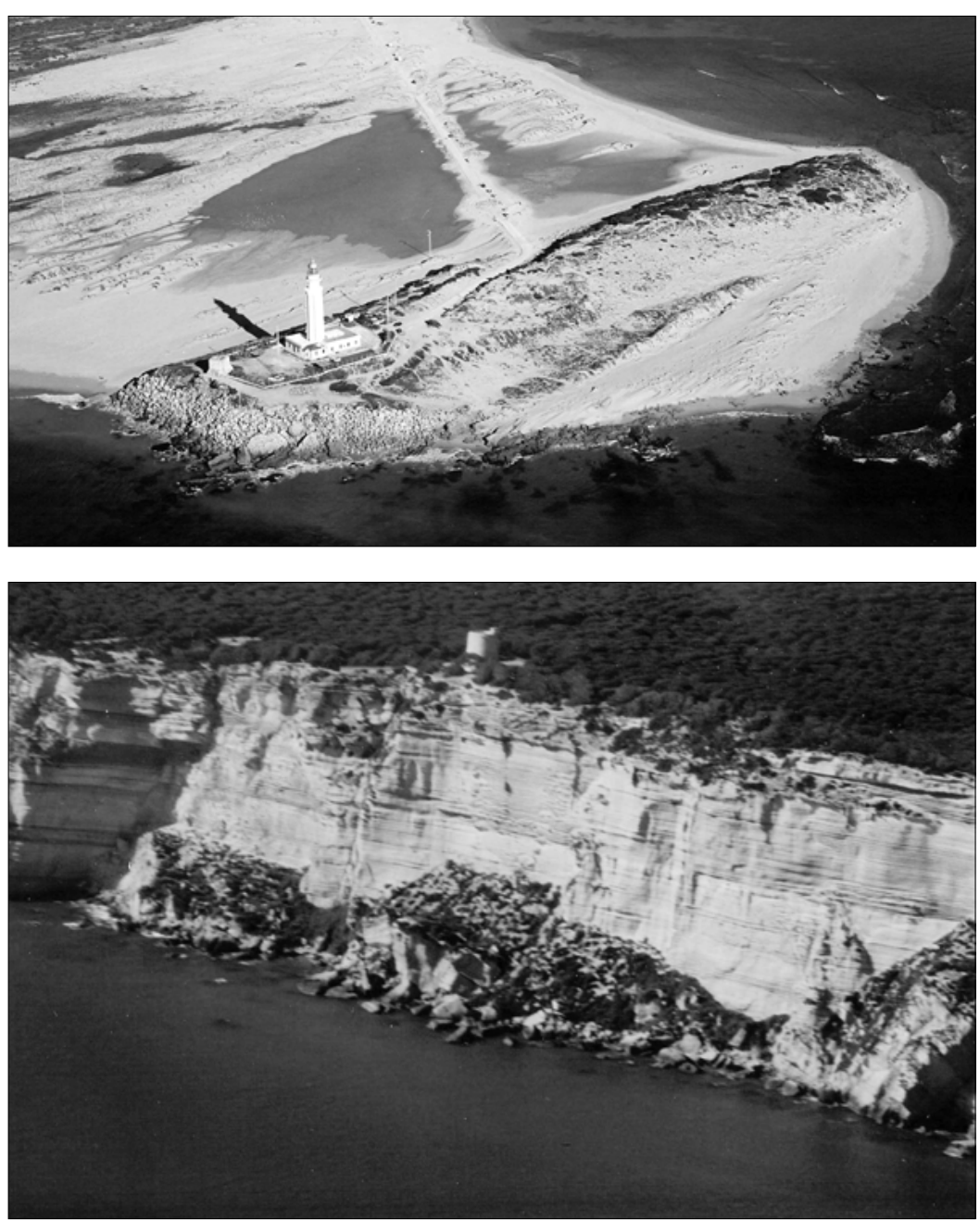


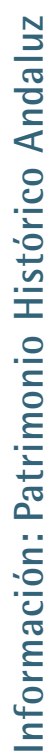

las funciones militares con las económicas. Algunas han desaparecido, otras han sido transformadas y otras sobreviven a veces en precario estado de conservación, pero todas mantienen privilegiadas situaciones en entornos naturales de complicado acceso. De esta forma al ser arquitecturas únicas y de desarrollo vertical en un marco natural su presencia adquiere una fuerte implantación y se convierten en referencias del territorio que dominan.

Este sistema, que ya hemos visto existía también en la costa de la actual provincia de Huelva, tiene un referente en la llamada Torre Alta de San Fernando que establecía comunicación con la Torre Tavira de Cádiz, ubicada en el centro urbano, así como en Torregorda y en el castillo de Sancti Petri. Desde ahí comenzaba la línea que continuaba en Chiclana con la llamada Torre Bermeja de planta circular, situada sobre un acantilado y en la actualidad casi absorbida por la trama urbana de la actual playa de la Barrosa, y la Torre del Puerco, en el límite de los términos de Chiclana y Conil asentada sobre un espacio geográfico plano lo cual le abría un campo visual amplísimo y que poseía estructura cilíndrica e interiormente abovedada.

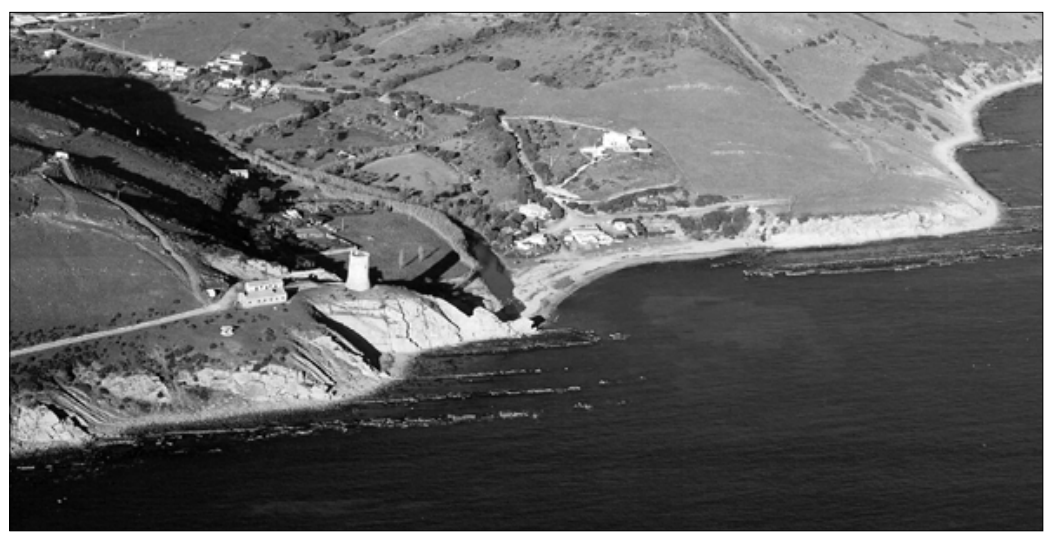

14. Tarifa. Torre de Guadalmesí.

15. Tarifa. Torre del Camarinal.

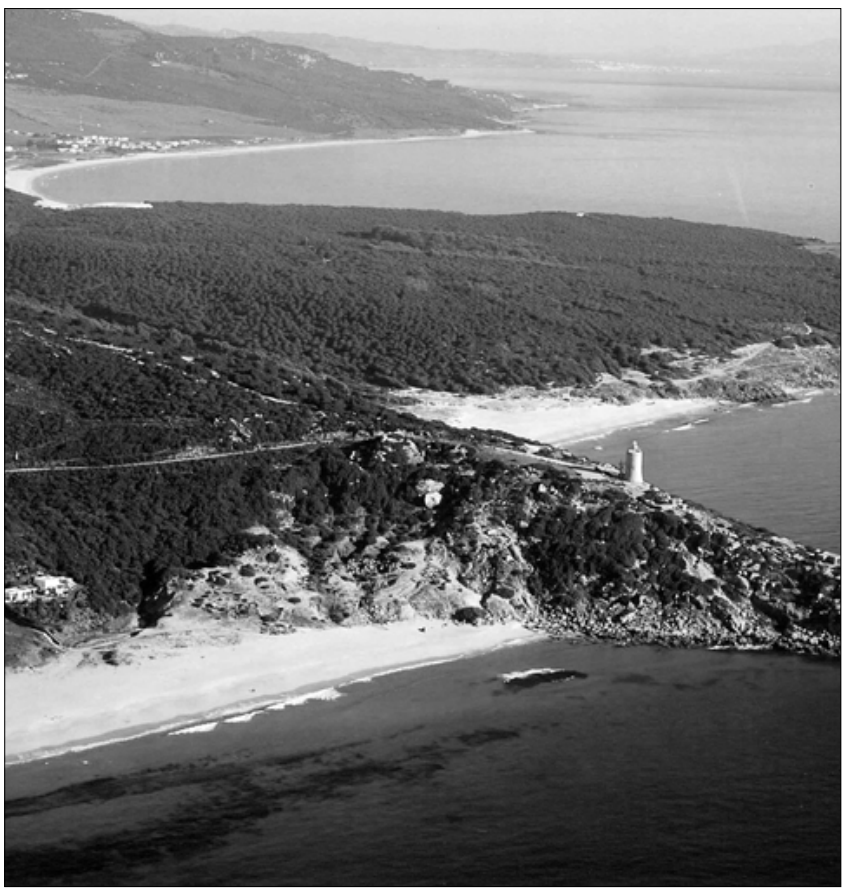

Extendiéndose hacia el sur, este sistema de detección y comunicación abarca a Conil de la Frontera. Es un núcleo urbano abocado al mar, con una tradicional actividad pesquera y almadrabera. Cuando en 1299 pasó a manos del Señorío de Guzmán se inició la construcción de la muralla y de la actual Torre de Guzmán, torre del homenaje del castillo. Esta atalaya situada en plena ciudad, lindera con la costa mantenía una doble función, la defensiva vinculada con la protección de Conil y del entorno y la económica relacionada con la búsqueda de los atunes que se pescaban en la almadraba y cuya chanca se sitúa en las proximidades de la misma. La cuestión de competencias almadraberas dio lugar a que durante el siglo XIX se destruyera el castillo haciendo peligrar esta torre que hoy día se eleva solitaria en el centro histórico de Conil.

En línea con la Torre de Guzmán se extendían por el litoral del término, las torres almenaras que, como decíamos, completaban el sistema defensivo. En Conil destaca la presencia de dos, cuya disposición controla toda la costa y que enlazan con la, ya citada, Torre del Puerco ubicada en el límite de Chiclana y Conil. La primera es conocida como Roche y esta situada sobre un acantilado en las proximidades del puerto, siendo utilizada en la actualidad como señal marítima. Al parecer, fue construida en el siglo XVI y posee planta cuadrada con talud en la base. La segunda, conocida como Torre Castilnovo, está situada en la frontera de la playa, en un amplio espacio descubierto que le confiere una especial presencia y dominio visual. Posee planta cuadrada y el acceso al interior se realiza a través de una escalera situada en la parte posterior. Además de estas torres, otras dos, hoy desaparecidas, oteaban el horizonte: Torre Blanca y Torre Atalaya.

Ya dentro del término de Vejer, en la playa del Palmar, se localiza Torrenueva, de planta troncocónica y situada sobre un promontorio de la playa en el límite de la pleamar.

Barbate 12 era una aldea vinculada a Vejer hasta que en 1938 se independizó. Su importancia en la zona sigue asociada a la cuestión pesquera y las almadrabas, actividad que hoy día se sigue ejerciendo. En su amplio litoral se localizan hasta tres de estas torres que, con su presencia, continúan dibujando el mapa defensivo de la costa atlántica. La Torre de Trafalgar, en la actualidad desmochada y situada junto al faro del mismo nombre, para cuya construcción se utilizaron, durante la segunda mitad del siglo XIX, los materiales de su derribo. Al parecer tenía dos pisos sobre bóvedas y una escalera de caracol para acceder al superior 13. Torre de Meca, construida durante el siglo XIX sobre el monte Meca, su perspectiva visual, con sus II metros y alzado troncocónico, es amplísima.

Y finalmente, la Torre del Tajo, de alzado troncocónico, con una altura de 14 metros y construida durante el siglo XVI sobre un acantilado "porque entre Trafalgar y Barbate hay mucha agua y no la puede 
defender la torre de Barbate ni la de Trafalgar y es de manera la costa que gente de a cavallo no puede allegar a saber daño en los que allí estuvieren"14. Existía además en Barbate un castillo llamado de Santiago que dominaba la desembocadura del río Barbate y del que en la actualidad sólo queda un monolito de recuerdo.

En esta misma línea que venimos comentando de pesquerías, se sitúa el castillo de la almadraba de Zahara de los Atunes. Un recinto amurado que además de proteger la costa, defendía los artilugios de la almadraba allí establecida. Era una muralla de planta cuadrada con torreones en los extremos y las dependencias de la almadraba y chanca en el interior. Fue mandado construir en el siglo XVI por los duques de Medina Sidonia y sus muros aún permanecen en pie.

\section{La bahía de Algeciras}

La bahía de Algeciras, que forma parte del Campo de Gibraltar, es un espacio geográfico situado en la parte meridional de la costa gaditana. Se extiende como frontera natural de los mares Atlántico y Mediterráneo y es y ha sido puerta natural para la comunicación con Africa y lugar de paso inevitable para la entrada en la península. Desde esta perspectiva se hacía imprescindible la protección con arquitecturas militares que asegurasen el espacio geográfico y de los recintos urbanos de las invasiones, especialmente las provenientes del mundo árabe. Así Tarifa y Algeciras fueron ciudades con murallas de importancia. Pero además la cuestión del Peñón de Gibraltar fue un aspecto que incidió desde el punto de vista bélico en la zona, hasta el punto que fue el origen de una ciudad y de la creación de algunos reductos defensivos interesantes.

Tarifa, la ciudad más al sur, es un ente urbano que desde época musulmana fue considerado enclave estratégico y en consecuencia defendido con la creación de murallas que la envolvían y enlazaban con su castillo. Este, llamado de Guzmán el Bueno, fue construido por Abderramán III y adaptado y modificado tras la conquista cristiana. Ambas defensas perviven aún. La muralla, alterada por el devenir histórico, mantiene, no obstante, sus torres y la llamada Puerta de Jerez, uno de los accesos de la primitiva ciudad.

El castillo, por su parte, situado sobre un saliente elevado que domina la ciudad y la costa presenta planta trapezoidal con los muros articulados por torres cuadradas que le confieren una sólida presencia. La Torre del Homenaje, la conocida como Torre de Guzmán el Bueno, quedó situada en el exterior del recinto y unido a él por una coracha.

No podían faltar, desde luego, las torres almenaras surcando el perfil de la costa. En el término de Tarifa podemos encontrar la llamada Torre de la Peña, de origen islámico y con planta rectangular, situada sobre un promontorio rocoso, y a la que se accede a través de escalones tallados en la roca. La Torre Guadalmesí, de planta circular con dos pisos y unos quince metros de altura y la de Camarinal, construida en el siglo XVII sobre el cabo de Gracia, presenta planta circular y fue transformada en faro ${ }^{15}$. En Tarifa hay que destacar también la presencia de la llamada Isla de las Palomas en cuyo extremo se sitúa la torre del mismo nombre, construida durante el siglo $\mathrm{XVI}$ con diecisiete metros de altura y reformada durante el siglo XVIII al ser convertida en faro 16 .

Algeciras tras el desarrollo musulmán que la convirtió en ciudad amurallada con alcázar fue casi abandonada, empezándose a recuperar durante el siglo XVIII a raíz de la conquista inglesa del Peñón de Gibraltar. El sistema defensivo musulmán fue destruido como consecuencia del abandono y de la expansión dieciochesca. En consecuencia y con el nuevo escenario bélico relacionado con el Peñón, sus defensas enlazan con la frontera con Gibraltar y la fundación de la Línea de la Concepción. Así destaca la isla de las Palomas, distinta a la de Tarifa, situada frente al Peñón y que fue abaluartada durante el siglo XVIII dirigiendo su línea de fuego hacia la Roca. Esto se complementaba con la marca defensiva de la Línea compuesta de dos fuertes, el de San Felipe y Santa

16. Tarifa. Vista de la Isla de las Palomas y de la torre del mismo nombre.

17. Manilva. Vista de Torre Chullera.
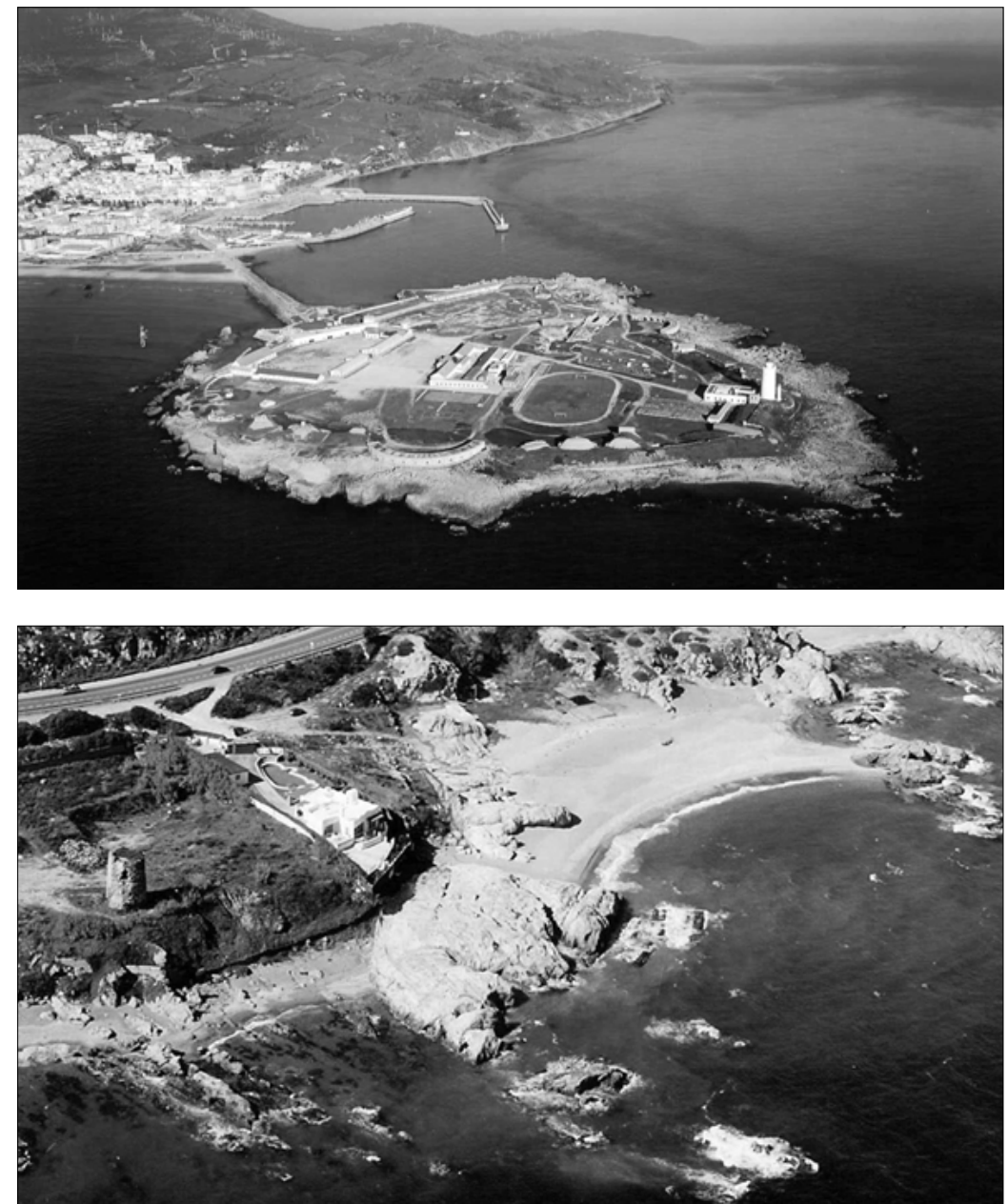
Bárbara, unidos por un lienzo amurado, y del que aún pueden apreciarse los restos del último.

También las torres almenaras ocuparon el espacio de estas ciudades. En el término de Algeciras se situó la conocida como la Torre del Fraile o del Canuto, del siglo XVI que domina la bahía algecireña y otras más que ya han desaparecido o cuyos vestigios son escasos. Para finalizar hay que mencionar la presencia de las casamatas o bunkers que hacen frente desde La Línea al Peñón y que fueron realizados durante la II Guerra Mundial. El conjunto de las torres de la zona atlántica enlazaba con las existentes en el Peñón de Gibraltar y ésta con la llamada Zona de Levante que ya se encuadra en la costa mediterránea. De esta manera la línea visual continuaba con la
Torre Nueva en el término de la Línea, construida en el siglo XVI con planta circular y con Torre Carbonera en el término de San Roque y Torre Nueva de Chullera ya en la provincia de Málaga.

Este era, en suma, el complejo sistema defensivo de la costa atlántica de Andalucía a lo largo de los siglos. La relación de espacios y arquitecturas, que en ningún momento ha pretendido ser exhaustiva, ha pretendido dar una visión conjunta que sirva de base para la valoración de los elementos, situándolos en su contexto geográfico e histórico y dándoles el sentido individual, colectivo y territorial que los convierten en parte del patrimonio cultural de esta zona del país.

\section{Bibliografía}

I. Sobre las mismas véase, MORA DE FIGUEROA, L. De: Torres de almenara de la costa de Huelva. Huelva, 1981. Actualmente, desde la Delegación Provincial de Cultura de Huelva se está redactado el expediente de delimitación del entorno de las mismas, siendo sus autores Juan Aurelio Pérez Macías y Nuria de la $O$ Vidal Teruel, en un intento de dotarlas de una mejor y adecuada protección. Dicho expediente ha sido utilizado en la redacción del presente trabajo, por lo que damos las gracias a sus autores y a la Delegación por la ayuda prestada.

2. Una disposición análoga presentaba el desaparecido castillo de Lepe, si bien, por los planos conocidos, éste era de planta cuadrada con ocho torres. Véase, CALDERÓN QUIJANO, J.A.: Las defensas del golfo de Cádiz en la Edad Moderna. Sevilla, 1974. Pág. 14, Fig. 15.

3. Sobre dicho proyecto consúltese, HERNÁNDEZ NÚÑ̃EZ, J. C.: "Encinasola y Cartaya en la defensa de la frontera hispanolusa a mediados del siglo XVIII. De castillo a cuartel". Laboratorio de arte. №. 9, 1996. Págs. 171-182.

4. GONZÁLEZ ESCOBAR, J. L.: El castillo de San Pedro (Huelva): función urbana y social. Huelva, 1993. POZO, F;; CAMPOS, J.M. Y BORJA, F:: Puerto histórico y castillo de Palos del Frontera. Huelva, 1996.

5. MANANTEAU, Löic y otros: Sanlúcar de Barrameda. Cádiz. 1991. T.II. Pág. 146.

6. El torreón existente en la actualidad es fruto de las reformas llevadas a cabo en el siglo pasado. Su configuración ha cambiado haciéndo visualmente más ligero. Todo lo contrario al que existía inicialmente.

7. Esta intervención en la ciudad de finales del siglo XVIII resulta de especial interés por cuanto suponía la reedificación de parte de la fachada urbana a la bahía. Además se establecía una intensa relación entre arquitectura militar y ciudad, relación que no existía anteriormente por cuanto los elementos militares siempre habín mantenido una distancia de seguridad con respecto a la ciudad. El sistema de financiación de las obras a través de la venta de los inmuebles también era un punto a considerar.
8. CALDERÓN QUIJANO, J.A. y otros: Cartografia Militar y Marítima de Cádiz. 15I3-1878. Sevilla, 1978. T.I. Fig. 592.

9. Idem. T.II. Fig. 693 y 694.

|0. Idem. T.I.l. Fig. 69|.

11. Sobre las tipologías de las torres véase VALDECANTOS, Rodrigo: Las Torres de Almenara del litoral de la Provincia de Cádiz (Las Torres de Marina). En Estudios de Historia y de Arqueología Medievales. T.XI. 1996. Pág. 48I-50I.

12. El estado de la cuestión de las torres de esta parte del litoral comprendido entre Barbate y Algeciras ha sido estudiado por SÁEZ RODRÍGUEZ, Angel: Almenaras en el Estrecho de Gibraltar. Las torres de costa de la Comandancia General del Campo de Gibraltar. Cádiz, 200I. A dicho estudio remitimos para una conocimiento más detallado de estas arquitecturas.

13. SÁEZ RODRÍGUEZ, Angel: Almenaras en el Estrecho... Op. Cit. Pág. 184

14. CALDERÓN QUIIJANO, J.A. y otros: Cartografía Militar .... Op. Cit. T.ll. Anexo, Fig. 8.

15. Para un mayor conocimiento de las torres almenaras de Tarifa remitimos a SÁEZ RODRÍGUEZ, Angel: Almenaras en la costa de Tarifa I en http://w.w.w.tarifaweb.com/cultura/aljaranda/num2O/art6.htm. Consulta realizada el 14 de julio de 2002 y Almenaras en la costa de Tarifa II en

http://w.W.W. tarifaweb.com/cultura/aljaranda/num2I/art5.htm. Consulta realizada el 14 de julio de 2002.

16. SÁEZ RODRÍGUEZ, Angel: Almenaras en el Estrecho..... Op. Cit. Pág. 213. 